\title{
PENINGKATAN NILAI KOGNITIF BIOLOGI MENGGUNAKAN MODEL BLANDED LEARNING BERBASIS SCHOOLOGY PESERTA DIDIK KELAS X4 IPA SMA N 4 METRO TAHUN PELAJARAN 2018/2019
}

\author{
Lilik Hernani ${ }^{1}$ \\ Anak Agung Oka ${ }^{2}$ \\ Triana Asih ${ }^{3}$ \\ ${ }^{1}$ SMA N 4 Metro \\ ${ }^{23}$ Program Studi Pendidikan Biologi Universitas Muhammadiyah Metro \\ E-mail: ${ }^{1}$ hernanililik4@gmail.com, ${ }^{2}$ anakagung5@gmail.com, ${ }^{3}$ asih.triana@yahoo.com,
}

\begin{abstract}
Changes in civilization, including technology, must be addressed appropriately by teachers. Therefore, learning strategies in education must also be adjusted. SMA Negeri 4 Metro Biology subjects have not used e-learning based learning. The use of existing facilities in schools has not been used optimally, such as available wifi networks. WiFi networks are only used on computer lessons and national examinations. The percentage of learning outcomes in the cognitive domain has not yet reached maximum completeness. The purpose of this Classroom Action Research is: To improve the learning outcomes of Biology Students in Class X4 IPA Senior High School 4 Metro Odd Semester 2018/2019 Academic Year by using Schoology-Based Blanded Learning model. The research method that will be used in this research is CAR (Room Action Research), or what we are often familiar with Class Action Research (CAR). The research was carried out in class X4 IPA of SMA N 4 Metro which was held by 32 people. Research conducted by collaborating between PDS Lecturers (School Lecturer Placement) and classroom teachers. The results of this study, Blanded Learning Based on Schoology can improve the learning outcomes of Biology Students of Class X4 IPA Senior High School 4 Metro Odd Semester 2018/2019 Academic Year. At the beginning of PTK students who reached KKM or students who completed as many as $56.25 \%$ and increased by $6.25 \%$ in the first cycle, which amounted to $62.5 \%$. And increased again in the second cycle by $25 \% \%$ of students who completed to $87.5 \%$.
\end{abstract}

Kata kunci: Blanded Learning, nilai, Schoology, PjBL

\section{PENDAHULUAN}

Pembangunan dalam bidang pendidikan diamanatkan dalam Peraturan Pemerintah Nomor 13 Tahun 2015 Pasal 1 tentang Standar Nasional Pendidikan bahwa Setiap daerah akan memiliki kualitas yang sama dalam bidang pendidikan dan tidak akan terjadi ketimpangan antara setiap daerah. Tujuan pendidikan yang tertuang di undang-undang dapat terwujud dengan baik, jika sumber daya manusia yang dihasilkan dari proses pendidikan tersebut dapat bersaing di era globalisasi.
Kemajuan suatu bangsa dapat diukur juga dari suatu sistem dan proses pendidikan yang ada di bangsa itu sendiri. Penggunaan Ilmu Pengetahuan Teknologi Komunikasi (IPTEK) salah satu cara untuk peserta didik menghadapi tuntutan zaman yang semakin hari semakin berkembang Kemendikbud (2017).

Perubahan peradaban termasuk di bidang teknologi harus disikapi dengan tepat oleh para guru. Oleh sebab itu, strategi pembelajaran di dunia pendidikan juga harus disesuaikan. SMA 
Negeri 4 Metro khususnya mata pelajaran Biologi belum menggunakan pembelajaran berbasis e-learning. Persentase nilai ranah kognitif juga belum mencapai ketuntasan maksimal.

Penggunaan fasilitas yang ada di sekolah belum digunakan secara maksimal, seperti jaringan wifi yang tersedia. Jaringan wifi hanya digunakan pada pelajaran komputer dan ujian nasional saja. Maka, untuk memaksimalkan nilai peserta didik, akan dilakukan Penelitian Tindakan Kelas (PTK) yang menggunakan pembelajaran e-learning.

Salah satu model pembelajaran yang menggabungkan antara pembelajaran konvesional dengan pembelajaran e-learning adalah pembelajaran blended learning. Sistem pembelajaran secara elektronik atau sistem E-learning (bisa menggunakan email ataupun sosial media) yang digabungkan dengan sistem pembelajaran konvensioanl (tatap muka langsung dengan murid di kelas seperti pengajaran pada umumnya), sistem pembelajaran ini dikenal sebagai blended learning (Armin, 2014).

Salah satu sosial media yang dapat digunakan untuk pembelajaran $e$ learning adalah Schoology. Schoology yang dikenal sebagai Learning Management System (LMS) atau Courses Management System (CMS), platform berbasis cloud menyediakan peralatan yang diperlukan untuk mengelola sebuah kelas online. Schoology sebagai jaringan sosial untuk sekolah dan lembaga pendidikan tinggi yang berfokus pada kolaborasi, yang memungkinkan pengguna untuk membuat, mengelola, dan berbagi konten akademis (Bibi, 2015).

Peserta didik pada jenjang Sekolah Menengah Atas memasuki tahapan operasional formal yaitu mereka mulai dapat mengembangkan alat baru untuk memanipulasi informasi, mudah berpikir abstrak, deduktif maupun induktif, lebih mengembangkan keterampilan intelektualnya mengintegrasikan apa yang mereka alami dengan teori dan konsep yang ada (Asih, 2018). Berdasarkan tingkatan ranah kognitif tersebut, salah satu model pembelajaran yang dirasa sesuai dengan tahapan tersebut adalah Project Base Learning (PjBL) karena langkah-langkah pembelajaran $\mathrm{PjBL}$ menunjang penrkembangan intelektual peserta didik melalui ide dan pengembangan proyek yang mereka desain dan lakukan sendiri, langkah-langkah tersebut antara lain; menentukan pertanyaan mendasar, mendesain perencanaan project, menyusun jadwal, memonitor peserta didik dan berkemajuan, menguji hasil, dan mengevaluasi pengalaman.Model pembelajaran $\mathrm{PjBL}$ juga merupakan salah satu model pembelajaran Scientifict Aprroach yang digunakan pada kurikulum 2013 revisi tahun 2016 (Sujarwanta dkk., 2018).

PjBL merupakan model pembelajaran bebasis proyek/riset sebagai inti pembelajaran yang di dalam sintaks pembelajaran terdapat metode ilmiah Scientifict Aprroach seperti menanya, menalar, mengumpulkan data, menyimpulkan, dan mengkomunikasikan (Zubaidah dkk., 2014). Pembelajaran berbasis proyek memotivasi peserta didik untuk belajar mandiri menemukan informasi sendiri dari berbagai sumber, seperti tim ahli, lingkungan sekitar, media dan internet. Peserta didik termotivasi bekerjasama dengan tim untuk menghasilkan ide-ide kreatif yang kemudian diwujudkan dalam suatu produk. Pembelajaran proyek ini juga melatih agar peserta didik berpikir kritis terhadap permasalahan kontekstual yang berkaitan dengan materi biologi melalui tema-tema yang mereka pilih, sehingga dapat meningkatkan kemampuan kognitif peserta didik mulai dari menganalisis, mensintesis, mengevaluasi, dan mencipta (Insyasiska dkk., 2017). 


\section{METODE}

Metode penelitian yang digunakan dalam penelitian ini yaitu CAR (Room Action Research), atau yang sering kita kenal dengan Penelitian Tindakaan Kelas (PTK). Penelitian dilaksanakan dikelas X4 IPA SMA N 4 Metro yang berjumlah 32 orang. Penelitian dilaksanakan dengan melakukan kolaborasi antara Dosen
PDS (Penempatan Dosen di Sekolah) dan guru kelas. Target atau indikator pencapaian PTK ini adalah jika nilai kognitif peserta didik X4 IPA sudah mencapai mencapai nilai $\mathrm{KKM} \geq 70$ sebanyak $80 \%$. Instrumen soal tes dianalisis melalui uji validitas dan reliabilitas, sedangkan instrumen observasi menggunakan lembar observasi dan dianalisis dengan skala penilaian.

\section{HASIL DAN PEMBAHASAN}

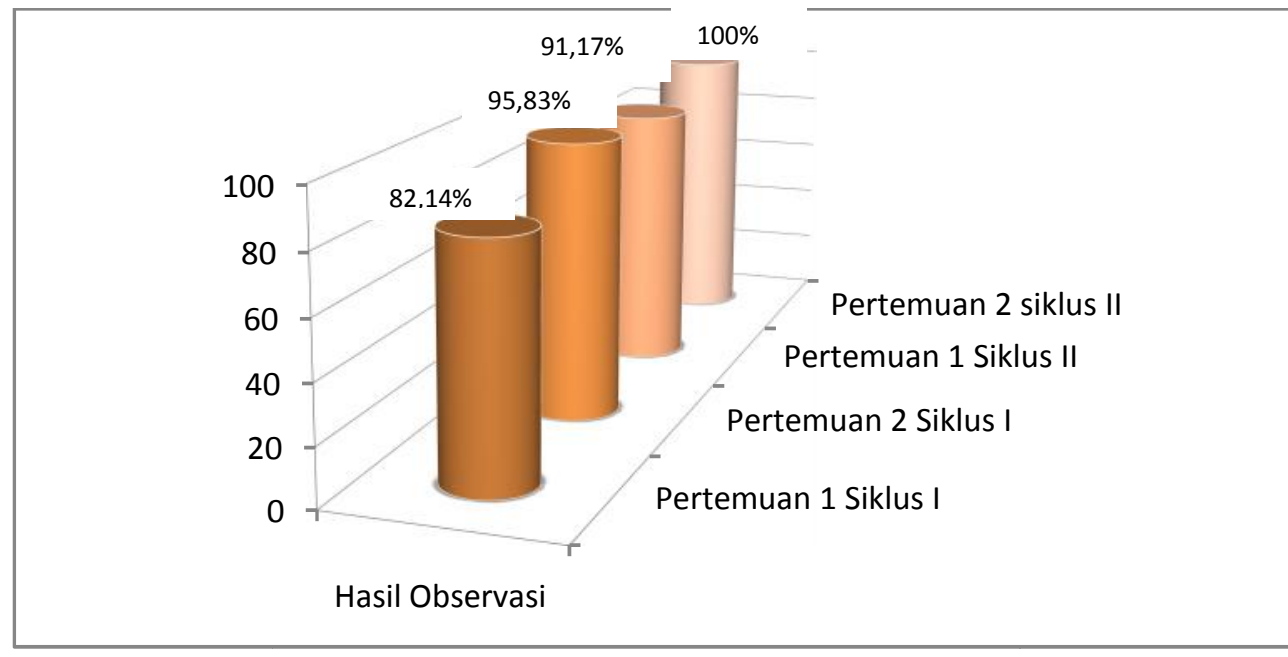

Gambar 1. Keterlaksanaan Model Pembelajaran Blanded Learning Berbasis Schoology dan PjBL

Berdasarkan Gambar 1 di atas, pelaksanaan proses pembelajaran sudah mencapai kriteria sangat baik, yang artinya proses pembelajaran pada pertemuan siklus I (pertemuan 1 dan 2) dan siklus II (petemuan 3 dan 4) sudah sesuai dengan langkah-langkah model pembelajaran blanded learning berbasis schoology dan PjBL. Karena tidak ada hambatan atau permasalahan dalam penerapan model pembelajaran tersebut. Maka, penilaian harian baik siklus I dan siklus II dapat valid dan dapat digunakan. 


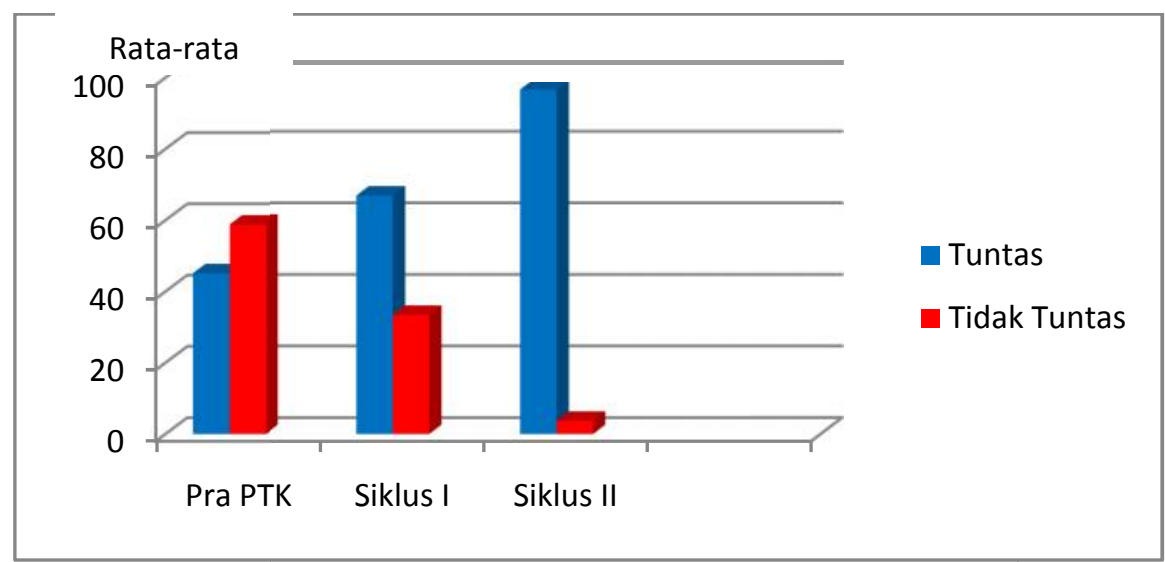

Gambar 2. Diagram Batang Peningkatan Nilai Peserta didik

Berdasarkan Gambar 2 di atas, Hasil penelitian pra-PTK sampai akhir siklus II diketahui bahwa terjadi peningkatan nilai peserta didik kelas $\mathrm{X} 4$ IPA semsester ganjil SMA Negeri 4 Metro Tahun Pelajaran 2018/2019. Pada awal pra PTK peserta didik yang mencapai KKM atau peserta didik yang dikatakan tuntas sebanyak $56,25 \%$ dan meningkat sebanyak $6,25 \%$ pada siklus I, yaitu sebesar $62,5 \%$. Dan meningkat lagi pada siklus II sebanyak $25 \% \%$ peserta didik yang tuntas menjadi $87,5 \%$.

Peningkatan terlihat signifikan, hal tersebut terjadi karena menggunakan model pembelajaran blanded learning berbasis schoology dan Project Based Learning (PjBL). Dukungan perkembangan teknologi informasi dan telekomunikasi serta tuntutan kompetisi global, e-learning dirasakan tidak sekedar media alternatif dalam melaksanakan pembelajaran, akan tapi e-learning telah diposisikan sebagai tools untuk mencapai kompetensi kompetitif global (Setiawan dkk., 2014). Survei menunjukkan bahwa akses internet dapat meningkatkan integritas murid dalam proses pembelajaran (Suana dkk., 2017).

Pembelajaran dengan e-learning dapat membimbing peserta didik untuk belajar secara mandiri sehingga pembelajaran dapat beralih dari pembelajaran yang berorientasipada guru (teacher centered), menjadi pembelajaran yang berorientasi pada peserta didik (student centered). Kurniawan (2014) mengungkapkan bahwa pembelajaran dengan berbantuan website dapat menjadikan pembelajaran tersebut berpusat pada peserta didik. Peserta didik secara mandiri bertanggung jawab untuk pembelajarannya.

Pembelajaran dengan e-learning berbasis schoology dan $\mathrm{PjBL}$ akan menjadikan peserta didik aktif, baik dalam proses pembelajaran di kelas, maupun di dalam kelas virtual learning. Peserta didik akan berusaha dan berinisiatif dalam merancanakan dan mencari materi secara mandiri. Aktivitas virtual learning peserta didik juga meningkat seiring dengan kemandirian peserta didik mengerjakan tugas dan diskusi secara virtual, sehingga dengan menggunakan e-learning dapat memperkaya pengetahuan peserta didik nilai belajar secara konvensional dan memperkuat model belajar konvensional melalui pengayaan konten dan pengembangan teknologi pendidikan Muhfahroyin dkk., 2018).

Model pembelajaran konvesional yang digunakan adalah model $\mathrm{PjBL}$, model pembelajaran berbasis proyek, model pembelajaran efektif digunakan dalam pembelajaran karena model pembelajaran ini mengutamakan kemampuan dan kreativitas peserta didik dalam mengikuti proses pembelajaran. Pembelajaran berbasis proyek adalah suatu model pembelajaran yang 
melibatkan suatu proyek dalam proses pembelajaran. Proyek yang dikerjakan oleh peserta didik dapat berupa proyek perseorangan atau kelompok dan dilaksanakan dalam jangka waktu tertentu secara kolaboratif, menghasilkan sebuah produk, yang hasilnya kemudian akan ditampilkan dan dipresentasikan (Jagantara, 2014).

Model pembelajaran PjBL yang digunakan dalam penelitian tindakan kelas ini, akan mengoptimalkan kemampuan peserta didik dalam mengikuti pembelajaran. Peserta didik akan belajar dengan proyek, proyek sebagai bentuk nyata dari materi pembelajaran yang dipelajari. Peserta didik akan mengerjakan proyek terkait dengan materi pembelajaran sehingga menghasilkan produk, peserta didik belajar secara nyata dan bermakna (meaningful learning). sejalan pendapat Kristanti (2016) model pembelajaran PjBL berpusat pada proses, berfokus pada masalah, unit pembelajaran bermakna dengan memadukan konsep konsep dari sejumlah komponen baik itu pengetahuan, disiplin ilmu atau lapangan. Pada pembelajaran berbasis proyek, kegiatan pembelajaranberlangsung secara kolaboratif dalam kelompok yang heterogen.Penambahan pembelajaran virtual learning berbasi schoology memperkuat model pembelajaran konvesional PjBL.

Dengan adanya bahan ajar interaktif yang ada pada materi schoology mendukung proses pembelajaran semakin baik, dan menambah wawasan peserta didik dalam menyelesaikan permasalahan dalam proyek. Sehingga, nilai peserta didik menjadi lebih baik dari siklus I dan lebih optimal kembali pada siklus II, hanya 4 peserta didik dari 32 peserta didik yang belum tuntas nilainya.

\section{KESIMPULAN}

Berdasarkan hasil penelitian tindak kelas yang dilakukan dengan menggunakan model pembelajaran blanded learning berbasis schoology dan Project based learning, maka dapat disimpulkan bahwa: Blanded Learning Berbasis Schoology dapat meningkatkan nilai Biologi Peserta didik Kelas X4 IPA SMA N 4 Metro Semester Ganjil Tahun Pelajaran 2018/2019. Pada awal pra PTK peserta didik yang mencapai KKM atau peserta didik yang dikatakan tuntas sebanyak $56,25 \%$ dan meningkat sebanyak $6,25 \%$ pada siklus I, yaitu sebesar $62,5 \%$. Dan meningkat lagi pada siklus II sebanyak $25 \% \%$ peserta didik yang tuntas menjadi $87,5 \%$.

\section{SARAN}

Peneliti menyarankan bagi guru, agar menerapkan model pembelajaran blanded learning berbasis schoology, dan model pembelajaran konvesional lain yang mendukung kurikulum 2013. Selalu aktif menggunakan akun schoology dalam proses pembelajaran e-learning.

\section{DAFTAR RUJUKAN}

Armin. 2014. Blended Learning, Implementasi E-Learning Di Politeknik Negeri Balikpapan. Jurnal Sains Terapan. 1(1): 48-53.

Asih, T. 2018. Perkembangan Tingkat Kognitif Peserta Didik di Kota Metro. Didaktika Biologi: Jurnal Pendidikan Biologi. 2(1): 9-17.

Bibi, S. 2015. Efektivitas Model Blended Learning Terhadap Motivasi Dan Tingkat Pemahaman Mahapeserta didik Mata Kuliah Algoritma Dan Pemrograman. Jurnal Pendidikan Vokasi, 5(1): 74-87.

Insyasiska, D., S. Zubaidah, H. Susilo. 2015. Pengaruh Project Based Learning terhadap Motivasi Belajar, Kreativitas, Kemampuan Berpikir Kritis, dan Kemampuan Kognitif Peserta didik pada Pembelajaran Biologi. Jurnal Pendidikan Biologi. 7(1): 9-21.

Jagantara, I.M.W., P.B. Adnyana., N.L.P.M. Widiyanti. 2014. 
Pengaruh Model Pembelajaran Berbasis Proyek (Project Based Learing) Terhadap Nilai Biologi Ditinjau dari Gaya Belajar Peserta didik SMA. Journal Program Pascasarjana Universitas Pendidikan Ganesha Program Studi IPA. 4(1), 1-13.

Kementrian Pendidikan dan Kebudayaan. 2017. Buku Guru Ilmu Pengetahuan Alam. Jakarta: Kemendikbud.

Kristanti, Y.D., S. Subiki, dan R.F. Handayani. 2016. Model Pembelajaran Berbasis Proyek (Project Based Learning Model) pada Pembelajaran Fisika Di SMA. Jurnal Pembelajaran Fisika. 5(2): 122-128.

Muhfahroyin., \& E. Susanto. 2018. The Implementation of E-Learning to Improve Students' Virtual Activities. Journal Physics: IOPP Conference Series. 1114(2018):012039.

Setiawan, W., Hana, M. N., \& Waslaluddin. (2014). Analisis Penerapan Sistem E-Learning
FPMIPA UPI Menggunakan Technology Acceptance Model (TAM). Jurnal Pengajaran MIPA, 19(1). 128-140.

Suana, W., N. Maharta, I.D.P. Nyeneng, S. Wahyuni. 2017. Design and Implementation Of SchoologyBased Blanded Learning Media For Basic Physics I Course. Jurnal Pendidikan IPA Indonesia, 6(1): 170-178.

Sujarwanta, A., HRA. Mulyani,. \& T Asih. 2018. Model of Scientific Learning Approach Project Based Learning (PjBL) Based On Practicum for Students Biology Teacher Candidate. Progressive and Fun Education (Profunedu) International Conference Proceeding. 145-158.

Zubaidah, S., Lia Y, I Wayan D, Ardian A, Pangestuti, Dyne R, Puspitasarim Hamim T.M, Alifa R, Zenia L. Kurniawati, Fatia R, Mar'atus S. 2014. Buku Guru Ilmu Pengetahuan Alam. Jakarta: Kemendikbud. 